\title{
И.С. Урманчеева
}

\section{ВОПЛОЩЕНИЕ ИНВАРИАНТНОГО СМЫСЛА ОБРАЗНЫМИ СИСТЕМАМИ ДИАЛЕКТА И ЛИТЕРАТУРНОГО ЯЗЫКА (НА ПРИМЕРЕ ПЕЧОРСКИХ И ОБЩЕРУССКИХ ФРАЗЕОЛОГИЧЕСКИХ ЕДИНИЦ)}

\begin{abstract}
Сопоставлению подвергаются печорские и общерусские фразеологические единицы, облекающие инварианты нравственно-иенностных суждений в разную образную форму. Выбор того или иного образа, устойчиво закрепившегося в системе литературного языка или диалекта, не может быть случайным. Сравнение образного основания диалектных и общерусских оборотов позволяет обнаружсть не только сходство, свидетельствующее о весьма близких мировоззренческих установках, но и особенности региональной картины мира.

Ключевые слова: говоры Низовой Печоры, печорская фразеология, фразеологическая вариантность, фразеологическая синонимия, образность, коды культуры.
\end{abstract}

Фразеологизмы используются для непрямого, образного означивания мира. Но фразеологические единицы (ФЕ) являются знаками особого рода, отличными как от словесных знаков, так и от знаковой функции сочетания слов [1. С. 131]. Фразеологизмы способны указывать на мир «чужим» денотатом, выполняющим роль образной гештальт-структуры [Там же. C. 132]. Описание фразеологизмов невозможно без обращения к двум аспектам: содержательному и формальному - и предполагает изучение инвариантов смысла и образных форм, в которые этот смысл кодируется языковым сознанием [2. С. 256-257].

Для реконструкции русской языковой картины мира, как правило, привлекаются общенародные языковые единицы, обычно прошедшие сито литературного языка. Но это искусственное ограничение, искусственное сужение границ исследования. Для полноты описания языковой картины мира в нее нужно добавить красок русских говоров.

Инварианты смысла облекаются в литературном языке и диалектах не всегда совпадающими образными оболочками. Описание образов, воплощающих одинаковый смысл в устойчивых выражениях, функционирующих в разных формах национального языка - литературной и диалектной, - может позволить приблизиться к пониманию и общеязыковой и региональной картины мира.

По мнению О.А. Корнилова, морально-ценностные суждения, подвергаемые образному лексическому оформлению в предикативных фразеологических единицах, «могут не только отражать универсальность общечеловеческого жизненного опыта безотносительно к этническим особенно- 
стям, но и отражать национально-специфические акценты осмысления бытия» [2. С. 257]. Вероятно, фразеологизмы и паремии способны передавать не только национальную, но и региональную специфику. Поэтому в статье сопоставим общеупотребительные устойчивые обороты с фразеологическими единицами говоров Низовой Печоры - говоров старообрядческого населения, проживающего в Усть-Цилемском районе Республики Коми в окружении иноэтнического ${ }^{1}$ (коми-зырянского, коми-пермяцкого) населения [4. С. 17-18]. Диалектоноситель иначе «ословливает» окружающий мир, рисует иную картину бытия, чем носители литературного языка, опираясь на возможности своего диалекта и развивая и обогащая их [5. С. 25].

Итак, проследим, как один и тот же смысл получает неидентичное образное оформление, причем рассмотрим разные случаи формального и образного несоответствия: от минимального (фразеологические варианты ${ }^{2}$ ) до максимального несовпадения (междиалектные фразеологические синонимы). Полагаем, что именно вариантные или синонимичные общерусские устойчивые выражения могут выступить своеобразным «фоном» для экспликации особенностей диалектной образной системы. Все печорские фразеологизмы приводятся по «Фразеологическому словарю русских говоров Нижней Печоры» (составитель Н.А. Ставшина) [9].

1. Лексическое варьирование в печорских и общерусских устойчивых выражениях неизбежно влечет изменение образной основы без изменения смысла, чему способствует идентичность синтаксических конструкций и лексико-грамматического состава оборотов.

Несовпадение «действующих лиц» в печорском фразеологизме как собака да росомаха жить и общерус. как кошка с собакой влечет существенное несоответствие сценариев-ситуаций. В общерусской фраземе разыграна бытовая сцена, основанная на стереотипном представлении о неуживчивости кошек и собак, сформированном эмпирическим опытом наблюдения за их повадками. Одной из образных основ печорского оборота является сцена охоты - традиционного занятия северного жителя: «...население Усть-Цилемской и Ижемской слобод жило исключительно промыслами: охотой и рыбной ловлей» [10. С. 65]. Росомаха ${ }^{3}$ - млекопитающее семейства куньих - обитает в тайге и лесотундре Евразии и имеет промысловое значение [11. Т. 15. С. 248], в Республике Коми распростра-

Контакты русских и коми и даже некоторые этносмешения не нарушали компактного очагового расселения русских. Такой изолированности, в свою очередь, способствовало проникновение в их среду старообрядцев [3. С. 24].

${ }^{2}$ Фонетическая, грамматическая, лексическая, семантическая, конструктивная вариантность фразеологических единиц подробно рассмотрена в других работах автора (см., например: [6-8] и др.). В настоящем исследовании остановимся лишь на некоторых примерах, не упоминавшихся в предыдущих работах.

${ }^{3}$ Выбор зоонима росомаха не в последнюю очередь обусловлен внутренними языковыми механизмами возникновения устойчивого выражения, в частности его ритмико-рифмической организацией (ср. «Иванушко-то как собака и росомака жывут ж жэной»: в компоненте росомака взрывной к заменяет фрикативный $x$ ). 
нена повсеместно. Росомаха, в отличие от кошки, животное не домашнее, одна из возможных ситуаций встречи собаки и росомахи - охота, причем самая вероятная и распространенная, что подтверждают диалектоносители: «Росомак не одну сотню бат добывал; росомаку собака подынет на дерево». Образ (гештальт ${ }^{1}$ ) oxоты - неотъемлемый фрагмент региональной картины мира печорского диалектоносителя.

Межэтнические контакты нашли отражение в печорской поговорке шиньгу маслом не испортишь (ср. общерус. кашу маслом не испортишь). Этнографизм шаньга - 'лепешка, выпекаемая из ячменной, ржаной, пшеничной муки, из пресного или кислого теста, с незагнутыми краями и открытой начинкой (из картошки, крупы, ягод, творогу и т.п.)' [13. Т. 2. С. 437] появился в говорах Низовой Печоры в результате межэтнических контактов русских с местным коми-зырянским населением. Это слово широко представлено в севернорусских и сибирских говорах, но, по одной из версий, в русский язык оно попало из коми языка [14. С. 317-319].

Лексико-конструктивные варианты тоже успешно воплощают идентичный смысл. Например, семантика 'женская хитрость, ловкость, изворотливость, смекалка' реализуется устойчивыми оборотами (печор.) баба пока с кровати падает, семь раз мужика обманет и (общерус.) пока баба с печи летит, семьдесят семь дум передумает [15. С. 35]. Конструктивная вариантность поддерживается идентичностью синтаксической модели, квазисинонимией компонентов кровать - печь (место для сна, отдыха), naдать - лететь, мифологическим символизмом квантитативов семь семьдесят семь (гиперболизированное удвоение семерки). Мнимое образное несоответствие заключается в описании одинаково парадоксальных действий семь раз мужика обманет - семьдесят семь дум передумает, отводящем женщине роль антагониста мужчины и ловкого, изворотливого существа.

В говорах Низовой Печоры большей частотностью употребления по сравнению с литературным языком обладает пословица отольются медведю коровьи слёзы. Так, «Словарь русских пословиц и поговорок» В.П. Жукова со ссылкой на И.М. Снегирева, В.И. Даля, М.И. Михельсона, М.А. Рыбникову фиксирует только два варианта этой паремии отольются кошке мышкины слёзки / отольются волку овечьи слёзы [Там же. С. 242243]. Сохранившаяся в печорских говорах пословица отольются медведю коровьи слёзы упоминается в «Собрании 2491 древних российских пословиц» А.А. Барсова (Москва, 1770 г.), в «Словаре русского языка XVIII в.», в словаре В.И. Даля «Пословицы русского народа» [16] и др. Она завершает градационный ряд общеизвестных оборотов, основанный на изоморфной репрезентации образов жертвы и обидчика: мышка - кошка, овца волк, корова - медведь. В подобных парадигмах пословиц наблюдается

\footnotetext{
1 Гештальm - комплексная, целостная функциональная мыслительная структура, упорядочивающая многообразие отдельных явлений в сознании и объединяющая динамические и статические аспекты отображаемого объекта или явления [12. С. 119].
} 
уже не столько варьирование, сколько чередование «действующих лиц» при едином сюжете с единой моралью [17. С. 292].

Необходимо отметить, что четкие границы между вариантами фразеологических единиц и отдельными фразеологизмами, передающими идентичный смысл, установить невозможно, особенно если они принадлежат к разным формам национального языка, таким как литературный язык и диалект. Часто речь идет о переходных, пограничных случаях, о гибридных единицах. Так, некоторые фраземы строятся по тождественным синтаксическим схемам и имеют совпадение в двух и более компонентах.

Например, употребляющаяся в говорах Низовой Печоры пословица не смейся, квас, над гущей, сам не закисни (скисни, загусни) по синтаксической структуре в точности соответствует общерусской паремии не смейся, горох, над бобами, сам будешь валяться под ногами [15. С. 221]. Идентичность синтаксической конструкции поддерживается множественными лексическими совпадениями. Тем не менее различия в использовании «действующих лиц», в ритмико-рифмической организации, в оформлении второй части двучленных пословиц позволяют рассматривать их только как промежуточные (гибридные) явления [18. С. 186] между фразеологической вариантностью и фразеологической дублетностью. Образ, который репрезентирует инвариант смысла 'не злорадствуй, чтобы не повторить печальную участь', в печорском выражении не носит узкорегионального характера, хотя и передает простой, крестьянский колорит за счет использования русской лингвокультуремы квас, тогда как образ гороха и особенно бобов интернационален. Кроме того, в печорском обороте реализуется гастрономический код культуры $^{1}$ в отличие от растительного в литературной пословице.

Гармонизация устойчивого выражения - одна из причин несоответствия образного основания. Так, смысл 'имя / название не должно детерминировать поступки’ в говорах Низовой Печоры передается пословицей хоть как назови, только в ступе не толки, ритмически и рифмически организованной, в отличие от общеизвестного выражения хоть горшком назови, только в печку не ставь, имеющего, правда, менее распространенные рифмованные варианты хоть гориком назови, только в печку не станови; хоть гориком называй, только в печку не сажай [16. С. 208].

Инвариантный смысл 'большое количество денег' передается поразному диалектными и общерусскими фразеологизмами: денег чёрт не унесёт [9. Т. 1. С. 203] - денег куры не клюют [20. С. 334]. Печорский образ подчеркивает нечистую, бесовскую природу денег, максимизирует негативное отношение к богатству. Библейско-мифологические образы реализуют в говорах Низовой Печоры семантику генетического, семейного родства: от лешего ангел не родится. Общерусская образная система ис-

\footnotetext{
${ }^{1}$ Под кодами культуры понимаются «вторичные знаковые системы, использующие разные материальные и формальные средства для кодирования одного и того же культурного содержания, соединяющегося в целом в картине мира, в мировоззрении данного социума» [19. С. 170].
} 
пользует для этого природные, растительные образы: от осины яблочко не родится [16. С. 629], которые можно назвать универсальными для передачи данного смысла (ср. печор. от берёзы ива не вырастет).

Диалектные фраземы нередко прибегают к более грубым, простым, «деревенским» образам. Такая особенность диалектной категоризации мира с непременным наличием в ней субъективных элементов, пейоративности, «пессимизма» [5. С. 41] давно замечена учеными. Так, в печорском варианте устойчивого оборота баба не лапоть - с ноги не пнёшь используются слова баба, nнуть, которые в литературном языке оцениваются как просторечные [21. Т. 1. С. 53; Т. 2. С. 123]. Общерусские выражения жена не сапог - с ноги не скинешь, жена не рукавица - с руки не стряхнёшь, за пояс не заткнёшь [15. С. 116] включают нейтральные лексемы жена, стряхнуть и разговорный компонент скинуть. Обувные образы ввиду своей культурной связи с телесным низом, ногами, в антропологической классификации занимающими нижний ярус, сами оказываются более низкими по сравнению с образами рук, рукавиц, пояса, относящихся к среднему ярусу. Русская безэквивалентная лексема лаnоть, имеющая коннотации простоты, бедности, лучше передает крестьянский дух деревни (лапти ассоциируются с бедными и простыми людьми по сравнению с сапогами, в которых щеголяли богатые и знатные [22. С. 375]).

Региональный колорит образов проявляется в использовании диалектных лексем для репрезентации инвариантного смысла. Так, семантика 'разность, непохожесть' выражается общерусскими устойчивыми фразами у всякой пташки свои замашки, всяк по-своему с ума сходит, у всякой избушки свои поскрипушки, всякий молодец на свой образец [15. С. 80]. В говорах Низовой Печоры этот же смысл воплощается фразеологической единицей всяк на свой копьл, где копьл (обл.) - 'деревянная колодка для изготовления обуви' [13. Т. 1. С. 332]. Не последнюю роль в выборе лексемы играет эвфоническая организация оборота, поэтому общераспространенной пословице всяк сверчок знай свой шесток в говорах Низовой Печоры соответствует всякий стареи знай свой ставеи, где ставеи (устар. и обл.) 'деревянная точеная чашка' [9. Т. 1. С. 154]. Эвфемистическому зооморфному коду культуры в печорских говорах противопоставляется антропный, к назидательному смыслу прибавляются циничные нотки, не завуалированные анималистическими образами.

Совпадение фразеологических единиц в двух и более компонентах не всегда сопровождается идентичностью синтаксических моделей. Так, инвариантный смысл 'кого-либо невозможно обмануть, провести, переубедить' в литературном языке передается просторечным фразеологизмом на кривой не объедешь [20. С. 430], а в говорах Низовой Печоры устойчивыми выражениями ни на простом, ни на вороном коне не объедешь / и на добром коне не объедешь / и на худой кобыле не объедешь. Лаконизму эллиптически неполной общерусской поговорки ${ }^{1}$ соответствуют пространность и степенность диалектной.

\footnotetext{
${ }^{1}$ О пропуске компонента лошадь см. [22. С. 358].
} 
Разное образное воплощение одного содержания может сопровождаться различием субъектно-объектных отношений внутри предикативной единицы. Печорский устойчивый оборот пуганый волком (медведем) и пня боится соответствует общеизвестному выражению пуганая ворона куста боится. Зооморфные образы играют в сюжете разные роли: в общерусском выражении на первый план выходит образ вороны, а сама причина испуга представляется неважной. В диалектной пословице, бытующей в суровом северном лесном краю, важно подчеркнуть негативные последствия от встречи с местными хищниками - волком и медведем.

Иные отношения между компонентами наблюдаются в печорском устойчивом обороте свой воз не в тягость по сравнению с общерусским своя ноша не тянет. Компонент воз возвращает нас к крестьянскому прошлому, к деревенскому быту.

Широкие вариативные возможности демонстрируют слова-компоненты имена собственные. Выбор конкретного имени, как правило, не влияет на создаваемый образ. Единственное условие - комичность звучания такого имени, фонетическая экспрессия, диминутивная фамильярная, пренебрежительная или уничижительная форма. Общерусской пословице бог не Микитка, он всё видит [16. С. 60] находим образные соответствия в говорах Низовой Печоры: бог не Тимошка, видит немножко (в окошко) / бог не Ванька Ефремихин (Ефремов) / бог не Яика, видит, кому тяжко.

2. Далее рассмотрим фразеологические единицы, в которых инвариантный смысл, передаваемый разными образными системами, опирается на общий семантический стержень - один общий для ФЕ значимый компонент.

Воплощение идеи 'чужое лучше' осуществляется разными образами, но опирается на семантический стержень чужой: общерус. в чужнх руках ломоть велик [15. С. 63], чужсой хлеб вкуснее, на чужом дворе и курица с гуся, в чужнм огороде огуриь вкусней [23] и печор. в чужсой лодке шука всегда большая.

Реалии крестьянского быта способствуют воплощению идеи 'находчивый, словоохотливый, остроумный человек’ в печорском обороте под лавкой слово не ищет, имеющем общий семантический стержень с литературным фразеологизмом за словом в карман не лезет.

Образную вариантность демонстрируют фразеологические единицы, выражающие идею 'большое скопление людей, теснота' и опирающиеся на общий адвербиальный локативный компонент негде: печор. негде ногу поставить / негде корове хвоста отбросить / негде курице клюнуть (ср. общерус. яблоку негде упасть / шагу негде ступить / плюнуть негде / иголку негде воткнуть / дохнуть негде / пальцем негде ткнуть [24. С. 373]). Образные системы литературного языка и диалекта реализуют идентичные коды культуры: акциональный и соматический (негде ногу поставить, шагу негде ступить, плюнуть негде, дохнуть негде, пальцем негде ткнуть), зооморфный (негде корове хвоста отбросить, негде курице клюнуть).

Символичность гастрономического образа хлеб находит отражение в печорском фразеологизме, воплощающем инвариантный смысл 'самостоятельно обеспечивать себя': на своём хлебе / на своих харчах. С общерус- 
ским фразеологизмом его объединяет стержневой компонент свой: жить своим трудом [20. С. 230].

3. Лексико-семантический стержневой компонент не единственная скрепа образных систем, воплощающих идентичную идею. Такой скрепой может быть синтаксическая модель - антитетическая, градуальная, ритмико-рифмическая. Сходство конструкций обеспечивается, как правило, незначимыми (служебными) компонентами.

Например, широко варьируемая в литературном языке модель, реализуемая в оборотах ни кола ни двора, ни кола ни двора ни куриного пера, ни ложки ни плошки, ни былинки ни травинки, в говорах Низовой Печоры имеет образные соответствия: ни дому ни лому, ни кошки ни ложки, ни коня ни двора. Конструктивное сходство наблюдается не только в синтаксической модели с повторяющимися сочинительными союзами, но и в ритмико-рифмической организации, причем в ущерб семантической однородности компонентов (дом - лом, кошка - ложка, конь - двор).

Такая же семантическая разнородность компонентов при идентичности синтаксической модели наблюдается в печорском выражении не крестом, mак пестом. Семантически разнородными подобные лексемы предстают вне конкретной ситуации и широкого культурного контекста. Но поскольку «субъект речи усматривает в словах-компонентах фразеологизма закодированный культурный смысл» [25. С. 96], лексемы крест и пест (печор.) 'крестообразная, чаще металлическая сетка на деревянной ручке' [13. Т. 2. C. 33] диалектоносителями символически интерпретируются как инструменты противоположных мер в достижении желаемого результата через образы морально-духовного или физического воздействия на человека. В общерусском обороте сюжетной основой является описание процесса стирки белья при помощи катка и рубеля [22. С. 458] для выражения идеи 'достижение желаемого любыми средствами': не мытьём, так катаньем.

Образы, воплощающие инвариантный смысл, нередко имеют квантитативные отличия (ср. вышеприведенные отольются кошке мышкины слёзки - отольются волку овечьи слёзы - отольются медведю коровьи слёзы). Такая же градуальная гипонимия компонентов создает образную основу печорского оборота не по годам - по месяиам расти и общерус. не по дням, а по часам с обязательным изоморфизмом частей, в данном случае временных отрезков: годы -месяџы, дни - часы.

Идентичность синтаксических моделей и служебных элементов не является залогом сходства образного оформления в подсистемах диалекта и литературного языка. Для выражения идеи 'свершившегося не исправить' литературный язык использует гештальт-структуру спора, столкновения: после драки кулаками не машут, а диалект опирается на сюжет традиционного занятия северного лесного жителя, связанного с деревообработкой: после стружки топором не чешут. Лесная тематика в печорских говорах создает образную основу, репрезентирующую инвариантный смысл 'совершить ошибку повторно': полезть на ту же ёлочку (ср. общерус. наступить на те же грабли). 
Единственной скрепой, объединяющей образные системы, воплощающие одну идею, может, при различии синтаксических конструкций, оставаться служебный компонент - невероятно важный, как, например, отрицательная частица не. Так, в печорском фразеологизме не даровой поп крестил благодаря частице не возникает эффект отрицания чего-то бесплатного, дешевого, а значит, ненужного, неподходящего или простого, незамысловатого, не сложно устроенного. Эта же идея воплощается другими образами в литературном языке: не лыком иит, не соломой крыт, не лаптем щии хлебать, не левой ногой сморкаться, не обсевок в поле [24. С. 244].

Такой же смысловой скрепой является частица не в печорском и общерусском оборотах на красоте не блины пекчи [9. Т. 2. С. 23] - с лица не воду пить [15. С. 282], конденсирующих идею незначимости внешних, эстетически оцениваемых данных по сравнению с другими свойствами и способностями избранника. Инвариантная ценностная установка о противопоставлении внешних и внутренних качеств человека с явным перевесом личностных положительных характеристик воплощается также в печорской пословице красоту не лизать <дурака не обтесать > .

Даже соединительный союз может быть смысловой скрепой, выражающей идею комплементарности, исчерпывающего характера образа: печор. главная еда - хлеб да вода - общерус. щ⿻и да каша - пищза наша, щзи да каша - мать наша [Там же. С. 367]. Лингвокультурная ценность гастрономических образов различна: щ⿻и и каша подчеркивают национальную специфику, тогда как хлеб и вода воплощают универсальный и вненациональный символ пищи в целом и простой крестьянской еды в частности.

4. Далее сопоставим диалектные и литературные фразеологические единицы, образные основы которых самостоятельны, не опираются на стержневые лексические компоненты. Тем не менее даже в таких оборотах можно обнаружить сходство, например, структурной модели без лексикосемантических соответствий. Так, печорский оборот отряхня ногу, воплощающий идею 'небрежно, нехотя (делать что-то)', строится по такой же регулярной модели ('деепричастие + существительное'), что и общеизвестная фразема спустя рукава, однако использует соматизм более низкого в ценностной иерархии яруса: в трехчастной композиции внешнего и внутреннего атласа тела нога относится к нижней части человека [25. С. 117118], а, как известно, в мифологической модели мира верх и низ - одно из основных противопоставлений [26. С. 660-661].

Воплощение общей семантической идеи, не поддержанное ни сходством синтаксических конструкций, ни общими лексическими знаменательными или служебными компонентами, может опираться на тематическую близость слов. Так, идея 'неспособный человек, ничего не умеющий делать’ воплощается в говорах Низовой Печоры глагольными компонентами со значением профессиональной деятельности: не ковать не молоть. В литературном языке для этой цели используются тематически однородные субстантивные компоненты: ни швец, ни жнец, ни в дуду игрец; ни в дудочку ни в сопелочку [24. С. 262]. Фразеосхема опирается не на языковые 
антонимы, а на лингвокультурные оппозитивы, создающие диатезу - прием утверждения среднего признака путем отрицания противоположных признаков [27. С. 426-427]: ковать и молоть (образы кузнеца и мельни$\kappa a)$ - основные занятия сельского жителя, не занятого в земледелии и животноводстве ${ }^{1}$.

Предметно-вещный код культуры по-разному передает инвариантный смысл 'нельзя оценивать человека / вещь по внешнему виду' в говорах и литературном языке: печор. не смотри на иубу, а смотри под шубу и общерус. по одёжке встречают, по уму провожают; не та иинель, что пуговицами блестит, а та, что греет [15. С. 253].

Завуалированный культурный код, маркирующий образное основание в подсистеме литературного языка, может отчетливо проявляться в диалекте. Так, литературный фразеологизм ииворот-навыворот реализует предметно-вещный код культуры неявно, скрыто, в то время как печорский оборот те же штаны, только пуговицами назад воплощает этот культурный код всей образной основой. Субидее 'наизнанку' соответствует субидея 'наоборот, задом наперед', и они, в свою очередь, формируют общую идею 'противоположно тому, как должно быть' (ср.: Всё равно, Федя, ты наличники неланно доспел, те же итаны, только пуговицами назад [9. Т. 2. C. 325]). Отметим, что этот смысл в литературном языке воплощается не только предметно-вещными образами: вверх ногами, вверх тормашками [24. C. 52].

Образные системы диалекта и литературного языка, выражающие инвариантный смысл, обнаруживают значительные черты сходства, поскольку их формирование осуществлялось в разных подсистемах одного национального русского языка. Тем не менее некоторые особенности образной системы северного диалекта, воплощенные в идиоматике и паремиологии, можно обнаружить и охарактеризовать.

Сходство. И общерусские и диалектные устойчивые выражения реализуют такие коды культуры, как гастрономический, растительный, зооморфный, предметно-вещный. Гастрономический код культуры проявляется в использовании названий традиционных русских кушаний, выполняющих роль русских лингвокультурем, - квас, блины, щци, каша [30].

Сюжетные роли и в диалектных и в литературных устойчивых выражениях играют традиционные для русской природы и крестьянского хозяйства дикие и домашние животные: курища, гусь, корова, кошка, волк, медведь, конь, сверчок, ворона. Растительный код культуры также равномерно реализуется в образных системах литературного языка и диалекта, диапазон фитонимов - от универсальных, общемировых до исконно русских: яблоко, горох, бобы, огурец, ива, береза, елочка. И в той и в другой подсистемах ис-

\footnotetext{
${ }^{1}$ Такое противопоставление носит весьма устойчивый характер и подтверждается диалектными данными других регионов, например псковской идиомой ковать и молоть 'пустословить, рассказывать небылицы' [28. Т. 14. С. 274], волгоградским оборотом ни куёт ни мелет 'о неумелом и малозначительном человеке' [29. С. 293].
} 
пользуются наименования остатков растений: пень, солома, обсевок - для указания на что-то незначительное, простое, ничтожное, презренное (пуганый волком и пня боится, не соломой крыт, не обсевок в поле).

Существенную роль в репрезентации инвариантного смысла в русских общеупотребительных и диалектных фразеологических единицах играют наименования предметов крестьянского, сельского быта, многие из которых относятся к русским лингвокультуремам: лавка, воз, ступа, лькко, лапоть, грабли, горшок, печь. Подобные лексемы являются участниками традиционных сцен русской жизни, реальных или гипотетических бытовых ситуаций, гештальт-структур: под лавкой слова не ищет, свой воз не в тягость, не лыком иит, не лаптем щуи хлебать, наступить на те же грабли, хоть гориком назови, только в печь не ставь.

Bсе описанные культурные коды коррелируют с традиционными занятиями сельского жителя - животноводством, хлебоуборочными и другими земледельческими работами, традиционными ремеслами и повседневными домашними занятиями.

Обнаруженное сходство свидетельствует о том, что русские, говорящие на разных диалектах (или на диалекте и литературном языке), имеют весьма близкое представление о мире, о чем свидетельствуют фразеологические единицы, отличающиеся по компонентному составу, но имеющие идентичный смысл.

Особенности. Фразеологическая система диалекта тесно связана с бытом, религиозными отправлениями, материальной и духовной национальной культурой, правилами общежития и обычаями языкового социума [31. C. 63-64].

Старообрядческая культура ${ }^{1}$ не могла не повлиять на фразеологию. При сопоставлении образных систем литературного языка и печорских говоров, реализующих идентичный смысл, становится заметным преобладание в печорских фразеологизмах образов библейско-мифологической, религиозной тематики: не крестом, так пестом; денег чёрт не унесёт; от лешего ангел не родится; бог не Тимошка, видит немножко; бог не Ванька Ефремихин; бог не Яика, видит, кому тяжко. Укрепившийся в УстьЦилемской округе раскол так называемого поморского согласия беспоповского толка [32. С. 59] не мог не сформировать иронического, фамильярного отношения к служителям церкви (не даровой поп крестил), что подтверждается метаязыковым комментарием носителей печорского диалекта: У нас-то в Усь-Цильме крестят бабки. Они на крещение ходят и только обедают, денег не берут. А попов у нас не любят - они за любой обряд денег берут. Редко, какой поп даром крестит [9. Т. 1. С. 195].

Результатом межъязыковых контактов жителей Печорского края с иноэтническим населением стали заимствования из финно-угорских языков,

\footnotetext{
${ }^{1}$ Печорский край пополнился новой миграционной волной «беглецов веры» в конце XVII - начале XVIII в., а Усть-Цильма стала «старообрядческим гнездом» на Печоре [32. C. 58-59].
} 
обозначающие специфические для данного региона реалии, которые настолько плотно вошли в повседневную жизнь, что это нашло отражение в образах, устойчиво закрепившихся в диалекте (шаньгу маслом не испортишь).

Нижняя Печора - это северный лесной край. Деревянные изделия, процесс деревообработки, северные лесные реалии упоминаются в устойчивых выражениях печорских говоров (после стружки топором не чешут; полезть на ту же ёлочку; пуганый медведем и пня боится). Даже компоненты-диалектизмы восходят к наименованиям деревянных предметов (всяк на свой копьл, всякий старец знай свой ставец).

Печорские говоры распространены в районах по рекам Печоре, Цильме, Пижме, где было развито не только личное, но и промысловое рыболовство [10. С. 92]. Сюжеты рыбной ловли, а также охоты находят отражение в устойчивых выражениях этого края (в чужой лодке щука всегда больше, как собака да росомаха жить).

Северный суровый климат обусловил обращение к таким образам, которые ему соответствуют: не смотри на шубу, а смотри под шубу (ср. использование гиперонима в общерусском обороте: по одёжке встречают, $a$ по уму провожают).

Печорские фразеологические единицы, совпадающие с общерусскими по смыслу, но облекающие инвариантную идею в иную образную оболочку, гораздо меньше реализуют соматический код культуры. Ср. общерус. 8 чужих руках ломоть велик; не левой ногой сморкаться; не смейся, горох, над бобами, сам будешь валяться под ногами; пальцем негде ткнуть; после драки кулаками не машут. Рассматриваемый инвариантный смысл в сопоставляемых печорских фразеологизмах в меньшей степени соотносится с соматическим кодом культуры.

Совершенно очевидно, что морально-нравственные установки, ценностные приоритеты людей, использующих в своей речи любую разновидность национального языка - литературную или диалектную, в ключевых своих чертах совпадают. Идиоматика и паремиология насчитывают большое, но все же ограниченное число тем и сюжетов. Интерес представляет воплощение морально-ценностных суждений в образную оболочку, поскольку образ фразеологизма (тропеическое основание внутренней формы) является «проводником» в пространство культуры [19. С. 146]. Сам выбор лексем, «действующих лиц», сюжетов, культурных кодов может быть интерпретирован с позиций языковой картины мира, в том числе и региональной.

Климатические условия северного лесного края, особенности быта, хозяйства и традиционных занятий печорцев, самобытная культура и нравственные устои старообрядцев запечатлелись в образной системе, воплотившей универсальные семантические идеи.

\section{Лuтература}

1. Телия В.Н. Русская фразеология: Семантический, прагматический и лингвокультурологический аспекты. М. : Школа «Языки русской культуры», 1996. 288 с. 
2. Корнилов O.A. Языковые картины мира как производные национальных менталитетов: [учеб. пособие]. 3-е изд., испр. М. : КДУ, 2011. 350 с.

3. На путях из Земли Пермской в Сибирь: очерки этнографии северноуральского крестьянства XVII-XX вв. / отв. ред. В.А. Александров. М. : Наука, 1989. 352 с.

4. Ли А.Д. Русские говоры Коми Республики. Сыктывкар : Изд-во Коми пед. ин-та, 1992. $106 \mathrm{c}$.

5. Радченко O.A., Закуткина Н.A. Диалектная картина мира как идиоэтнический феномен // Вопросы языкознания. 2004. № 6. С. 25-48.

6. Урманчеева И.С. Печорские фразеологизмы на фоне общерусских инвариантов // Язык и культура. Новосибирск. 2014. № 14. С. 7-12.

7. Урманчеева И.С. Лексическое варьирование печорских фразеологизмов в сопоставлении с общерусскими // Вестник Вятского государственного гуманитарного университета. 2016. № 4. С. 75-82.

8. Урманчеева И.С. Ритмико-рифмическая организация как проявление конструктивной вариантности печорских и общерусских фразеологизмов // Вестник Томского государственного университета. Филология. 2017. № 50. С. 125-134.

9. Фразеологический словарь русских говоров Нижней Печоры : в 2 т. / сост. Н.А. Ставшина. СПб. : Наука, 2008. Т. 1.416 с.; Т. 2. 420 с.

10. Белищер В.Н. Очерки по этнографии народов коми XIX - нач. XX в. М. : Изд-во AH CCCP, 1958. 394 c.

11. Новая иллюстрированная энциклопедия. М. : Большая Российская энциклопедия, 2004. 256 с.: ил.

12. Попова 3.Д., Стернин И.А. Когнитивная лингвистика. М. : АСТ : ВостокЗапад, 2010. 314, [6]c.

13. Словарь русских говоров Низовой Печоры : в 2 т. / под ред. Л.А. Ивашко. СПб. : Филол. ф-т СПбГУ, 2003. Т. 1. 553 с.; Т. 2. 470 с.

14. Мызников C.A. Атлас субстратной и заимствованной лексики русских говоров Северо-Запада. 2-е изд., испр. и доп. СПб. : Наука, 2007. 395 с.

15. Жуков В.П. Словарь русских пословиц и поговорок. 9-е изд., стер. М. : Рус. яз., 2002. $544 \mathrm{c}$.

16. Мокиенко В.М., Никитина Т.Г., Николаева Е.К. Большой словарь русских пословиц. М. : ОЛМА Медиа Групп, 2010. 1024 с.

17. Алефиренко Н.Ф., Семененко Н.Н. Фразеология и паремиология [учеб. пособие]. М. : Флинта : Наука, 2009. 344 с.

18. Жуков В.П., Жуков А.В. Русская фразеология. М. : Высш. шк., 2006. 408 с.

19. Ковшова М.Л. Лингвокультурологический метод во фразеологии: Коды культуры. М. : Книжный дом «ЛИБРОКОМ», 2012. 456 с.

20. Федоров А.И. Фразеологический словарь русского литературного языка. 3-е изд., испр. М. : Астрель : АСТ, 2008. 878, [2] с.

21. Словарь русского языка : в 4 т. / АН СССР, Ин-т рус. яз. ; под ред. А.П. Евгеньевой. 3-е изд., стер. М. : Рус. яз., 1985. Т. 1. А-Й. 1985. 696 с.; 1986. Т. 2: К-О. 736 с.

22. Бирих А.К., Мокиенко В.М., Степанова Л.И. Русская фразеология: Историкоэтимологический словарь: ок. 6000 фразеологизмов / СПбГУ; Межкаф. словарный каб. им. Б.А. Ларина ; под ред. В.М. Мокиенко. 3-е изд., испр. и доп. М. : Астрель : АСТ : Хранитель, 2007. 926, [2] с.

23. Зимин В.И. Словарь-тезаурус русских пословиц, поговорок и метких выражений. М. : АСТ-ПРЕСС КНИГА. 736 с. (Настольные словари русского языка).

24. Жуков В.П., Сидоренко М.И., Шкляров В.Т. Словарь фразеологических синонимов русского языка: ок. 730 синоним. рядов / под ред. В.П. Жукова. М. : Рус. яз., 1987. $448 \mathrm{c}$.

25. Гудков Д.Б., Ковшова М.Л. Телесный код русской культуры: материалы к словарю. М. : Гнозис, 2007. 288 с. 
26. Мифология: энцикл. / гл. ред. Е.М. Мелетинский. М. : Большая Российская энциклопедия : Дрофа, 2008. 736 с.

27. Введенская Л.А. Стилистические фигуры, основанные на антонимах // Введенская Л.А. Словарь антонимов русского языка. М. : Астрель : АСТ, 2008. 445, [3] с.

28. Псковский областной словарь с историческими данными. СПб. : Изд-во СПбГУ, 2004. Вып. 14. 388 с.

29. Мокиенко В.М., Никитина Т.Г. Большой словарь русских поговорок. М. : ОЛМА Медиа Групп, 2008. 784 с.

30. Россия: Большой лингвострановедческий словарь / под общ. ред. Ю.Е. Прохорова. М. : АСТ-ПРЕСС КНИГА, 2009. 736 с.: ил. (Фундаментальные словари).

31. Черданщева T.3. Идиоматика и культура (постановка вопроса) // Вопросы языкознания. 1996. № 1. С. 58-70.

32. Гунин Г.П. По Нижней Печоре. М. : Искусство, 1979. 162 с.

Expression of the Invariant Meaning by Figurative Systems of the Dialect and the Literary Language (On the Example of Pechora and All-Russian Phraseological Units)

Vestnik Tomskogo gosudarstvennogo universiteta. Filologiya - Tomsk State University Journal of Philology. 2019. 61. 98-112. DOI: 10.17223/19986645/61/6

Irina S. Urmancheeva, Pitirim Sorokin Syktyvkar State University (Syktyvkar, Russian Federation). E-mail: isurman@rambler.ru

Keywords: dialects of Lower Pechora, Pechora phraseology, phraseological alternativeness, phraseological synonymy, figurativeness, culture codes.

The aim of the article is to compare the Pechora and All-Russian phraseological units (phraseological units and paroemias proper), in which invariants of moral and axiological judgments are subjected to a non-identical figurative fixation. The article analyzes phrasemes used in the territory of the distribution of the Pechora dialects (speech of native Russian residents of settlements located along the Pechora River and its tributaries Pizhma, Tsilma and Neritsa) in comparison with all-Russian phraseological units. The usage and general distribution of the phrases were established according to the phraseological and paroemiological dictionaries of the Russian language. Pechora phraseological units are given according to the Phraseological Dictionary of Russian Dialects of the Lower Pechora compiled by N.A. Stavshina. The study used mainly the method of contrastive (comparative) analysis. The images of the phraseological units, which are guides to the cultural space, were interpreted as part of the linguocultural method in phraseology developed by V.N. Teliya, M.L. Kovshova, D.B. Gudkov, and others. To explicate the differences between the Pechora and all-Russian phrasemes, the method of linguistic (synchronous) description and elements of an etymological analysis were used. In the course of the study of phraseological units that translate identical meanings by the figurative systems of the dialect and the literary language, a different degree of the formal and figurative differences in the phrasemes is revealed: from the minimum (lexical and constructive variants that become intermediate, hybrid units) to the maximum (phraseological synonyms). The expression of the invariant meaning by the phraseological units of the dialect and the literary language is based on the similarity of syntactic models, the lexical and grammatical composition of the units, and is also supported by notional or functional semantic connectors, by the thematic relatedness of words and, finally, by words' correlation with one culture code. The following conclusions were made. (1) All-Russian and dialect phraseological units represent gastronomic, vegetative, zoomorphic and material cultural codes that correlate with the traditional occupations of a rural resident: animal husbandry and farming, daily household chores. A significant role in the representation of the invariant meaning in the all-Russian and dialect phraseological units is played by figurative components: names of objects of peasant, rural life, names of domestic and wild animals, plants. This is the similarity of the figurative systems of the dialects of the Lower Pechora and the literary language. (2) The figurative basis of the Pechora phraseological units that express the invariant meaning and have 
figurative and semantic correspondences in the literary language was formed under the influence of Old Believer traditions, climatic conditions of the Pechora region, and reflected the interethnic contacts of the Russian and Finno-Ugric population, traditional occupations and crafts of the northern forest resident, everyday realities and rural lifestyle.

\section{References}

1. Teliya, V.N. (1996) Russkaya frazeologiya: Semanticheskiy, pragmaticheskiy $i$ lingvokul 'turologicheskiy aspekty [Russian phraseology: Semantic, pragmatic and linguocultural aspects]. Moscow: Shkola "Yazyki russkoy kul'tury".

2. Kornilov, O.A. (2011) Yazykovye kartiny mira kak proizvodnye natsional'nykh mentalitetov [Language pictures of the world as derivatives of national mentalities]. 3rd ed. Moscow: KDU.

3. Aleksandrov, V.A. (ed.) (1989) Na putyakh iz Zemli Permskoy v Sibir': ocherki etnografii severnoural'skogo krest'yanstva XVII-XX vv. [On the paths from the land of Perm to Siberia: Essays on the ethnography of the northern Urals peasantry of the 17th - 20th centuries]. Moscow: Nauka.

4. Li, A.D. (1992) Russkie govory Komi Respubliki [Russian dialects of the Komi Republic]. Syktyvkar: Komi State Pedagogical University.

5. Radchenko, O.A. \& Zakutkina, N.A. (2004) Dialektnaya kartina mira kak idioetnicheskiy fenomen [The dialect picture of the world as an idio-ethnic phenomenon]. Voprosy yazykoznaniya. 6. pp. 25-48.

6. Urmancheeva, I.S. (2014) Pechorskie frazeologizmy na fone obshcherusskikh invariantov [Pechora phraseological units against the background of all-Russian invariants]. Yazyk $i$ kul'tura. Novosibirsk. 14. pp. 7-12.

7. Urmancheeva, I.S. (2016) Lexical variation of Pechora idioms comparing to allRussina ones. Vestnik Vyatskogo gosudarstvennogo gumanitarnogo universiteta. 4. pp. 75-82. (In Russian).

8. Urmancheeva, I.S. (2017) Rhythm and rhyme organisation as manifestation of constructural variability of Pechora and all-Russian phraseological units. Vestnik Tomskogo gosudarstvennogo universiteta. Filologiya - Tomsk State University Journal of Philology. 50. pp. 125-134. (In Russian). DOI: 10.17223/19986645/50/8

9. Stavshina, N.A. (2008) Frazeologicheskiy slovar' russkikh govorov Nizhney Pechory: $v$ 2 t. [Phraseological dictionary of Russian dialects of the Lower Pechora: in 2 volumes]. St. Petersburg: Nauka.

10. Belitser, V.N. (1958) Ocherki po etnografii narodov komi XIX-nach. XX v. [Essays on the ethnography of the Komi peoples in the 19th - early 20th centuries]. Moscow: USSR AS.

11. Gorkin, A.P. (ed.) (2004) Novaya illyustrirovannaya entsiklopediya [The new illustrated encyclopedia]. Moscow: Bol'shaya Rossiyskaya entsiklopediya.

12. Popova, Z.D. \& Sternin, I.A. (2010) Kognitivnaya lingvistika [Cognitive Linguistics]. Moscow: AST: Vostok - Zapad.

13. Ivashko, L.A. (ed.) (2003) Slovar'russkikh govorov Nizovoy Pechory: $v 2$ t. [Dictionary of Russian dialects of the Lower Pechora: in 2 volumes]. St. Petersburg: Faculty of Philology of St. Petersburg State University.

14. Myznikov, S.A. (2007) Atlas substratnoy i zaimstvovannoy leksiki russkikh govorov Severo-Zapada [The atlas of substrate and borrowed vocabulary of Russian dialects of the North-West]. 2nd ed. St. Petersburg: Nauka.

15. Zhukov, V.P. (2002) Slovar' russkikh poslovits i pogovorok [Dictionary of Russian proverbs and sayings]. 9th ed. Moscow: Rus. yaz.

16. Mokienko, V.M., Nikitina, T.G. \& Nikolaeva, E.K. (2010) Bol'shoy slovar' russkikh poslovits [A large dictionary of Russian proverbs]. Moscow: OLMA Media Grupp.

17. Alefirenko, N.F. \& Semenenko, N.N. (2009) Frazeologiya i paremiologiya [Phraseology and paroemiology]. Moscow: Flinta: Nauka. 
18. Zhukov, V.P. \& Zhukov, A.V. (2006) Russkaya frazeologiya [Russian phraseology]. Moscow: Vyssh. shk.

19. Kovshova, M.L. (2012) Lingvokul'turologicheskiy metod vo frazeologii: Kody kul 'tury [Linguoculturological method in phraseology: Codes of culture]. Moscow: Knizhnyy dom "LIBROKOM".

20. Fedorov, A.I. (2008) Frazeologicheskiy slovar' russkogo literaturnogo yazyka [Phraseological Dictionary of the Russian Literary Language]. 3rd ed. Moscow: Astrel': AST.

21. Evgen'eva, A.P. (ed.) (1985-1986) Slovar' russkogo yazyka: $v 4 t$. [Dictionary of the Russian language: in 4 volumes]. Vols 1-2. 3rd ed. Moscow: Rus. yaz.

22. Birikh, A.K., Mokienko, V.M. \& Stepanova, L.I. (2007) Russkaya frazeologiya: Istorikoetimologicheskiy slovar': ok. 6000 frazeologizmov [Russian phraseology: Historical and etymological dictionary: c. 6000 phraseological units]. 3rd ed. Moscow: Astrel': AST: Khranitel'.

23. Zimin, V.I. (2017) Slovar'-tezaurus russkikh poslovits, pogovorok $i$ metkikh vyrazheniy [The Thesaurus Dictionary of Russian Proverbs, Sayings and Apt Expressions]. Moscow: AST-PRESS KNIGA.

24. Zhukov, V.P., Sidorenko, M.I. \& Shklyarov, V.T. (1987) Slovar'frazeologicheskikh sinonimov russkogo yazyka: ok. 730 sinonim. ryadov [Dictionary of phraseological synonyms of the Russian language: c. 730 synonymic rows]. Moscow: Rus. yaz.

25. Gudkov, D.B. \& Kovshova, M.L. (2007) Telesnyy kod russkoy kul tury: materialy k slova$r y u$ [The corporal code of Russian culture: materials for the dictionary]. Moscow: Gnozis.

26. Meletinskiy, E.M. (ed.) (2008) Mifologiya: entsikl. [Mythology: An encyclopedia]. Moscow: Bol'shaya Rossiyskaya entsiklopediya: Drofa.

27. Vvedenskaya, L.A. (2008) Slovar' antonimov russkogo yazyka [Dictionary of antonyms of the Russian language]. Moscow: Astrel': AST.

28. Lutovinova, I.S. (ed.) (2004) Pskovskiy oblastnoy slovar's istoricheskimi dannymi [Pskov Regional Dictionary with Historical Data]. Is. 14. St. Petersburg: St. Petersburg State University.

29. Mokienko, V.M. \& Nikitina, T.G. (2008) Bol'shoy slovar' russkikh pogovorok [A large dictionary of Russian sayings]. Moscow: OLMA Media Grupp.

30. Prokhorov, Yu.E. (ed.) (2009) Rossiya: Bol'shoy lingvostranovedcheskiy slovar' [Russia: The Big Linguistic Country Study Dictionary]. Moscow: AST-PRESS KNIGA.

31. Cherdantseva, T.Z. (1996) Idiomatika i kul'tura (postanovka voprosa) [Idiomatics and culture (formulation of the question)]. Voprosy yazykoznaniya. 1. pp. 58-70.

32. Gunin, G.P. (1979) Po Nizhney Pechore [Along the Lower Pechora]. Moscow: Iskusstvo. 